\title{
La construcción de un éxito. Así se hizo nuestra sanidad pública
}

Arcadi Gual

Hoy nos rodean crisis de toda índole. Hoy la sanidad pública está cuestionada y muchos piensan que está en peligro. Hoy hay profesionales del mundo sanitario que se encuentran amenazados o al menos viven su futuro con preocupación. Y de golpe aparece un libro con un título sorprendente: $L a$ construcción de un éxito. Así se hizo nuestra sanidad pública. ¿Éxito? Realmente, ¿el Sistema Nacional de Salud merece ser calificado de éxito?

Convendrán conmigo en que, ante tanta preocupación, hablar de éxito es cuando menos sorprendente. Pero si desde el ámbito de la educación médica nos referimos a este reciente título, que puede encontrarse en las librerías, es porque cuenta algo que resulta cierto, que no es cuestionable, que alguien debía contar y que contarlo puede ayudar a salvaguardar la joya del Sistema Nacional de Salud que disfrutamos. Felicidades a su autor, Juli de Nadal i Caparà, y a sus colaboradores, Pedro Sabando y Lluís Bohigas, que han contado aquello que posiblemente nadie más podía contar tras la pérdida de Ernest Lluch.

A través de casi unas 300 páginas, encontrarán un relato amable vivido por su autor y colaboradores que resigue el antes y el después de la formación de grado, la formación de especialistas, el sistema sanitario público y la formación en investigación, el hito de la Ley General de Sanidad y, finalmente, la evolución del sistema para cubrir y adaptarse a los cambios sociales.

El libro tiene un cebo que curiosamente permite interesar a muy diferentes sectores de la población. Interesará, no lo duden, al médico sénior que revivirá recuerdos personales y también al médico joven que podrá reflexionar de cómo se gestó el sistema en el que trabaja y que, como sistema, es casi tan joven como él. Pero también descubrirá interés en su lectura el ciudadano que, alejado de la medicina, la necesita o la necesitará en breve. Y podrá descubrir que el Sistema Nacional de Salud es un sistema vivo que nació no sin superar numerosas dificultades, y que hay que alimentar y proteger desde la base. El Sistema Nacional de Salud no es un regalo caído del cielo, sino algo que hemos construido entre todos. No es fácil que nos lo quiten, pero gestores inexpertos podrían desbaratarlo. Conocerlo mejor nos ayudará a protegerlo.

Lean el libro y comprenderán mejor que el Sistema Nacional de Salud es una joya. Léanlo y lo protegerán mejor
Juli de Nadal i Caparà. La construcción de un éxito. Asíse hizo nuestra sanidad pública. Barcelona: Ediciones La Lluvia; 2016.

(c) 2016 FEM 